\title{
CONSTRUINDO CAMINHOS PARA A TROCA DE SABERES: PRODUÇÃO E INCORPORAÇÃO DE TECNOLOGIAS APROPRIADAS.
}

\author{
Maria Lígia Mohallem Carneiro ${ }^{1}$ \\ Eliane Marina Palhares Guimarães ${ }^{2}$ \\ Salete Maria de F. Silqueira de Resende ${ }^{3}$ \\ Andréia Rodrigues Moreira ${ }^{4}$
}

\section{INTRODUÇÃO}

O Pólo de Capacitação, Formação e Educação Permanente de Pessoal para Saúde da Família (PCFEP-SF) da Universidade Federal de Minas Gerais-UFMG, foi criado a partir do convênio 2229/98, celebrado com o Ministério da Saúde. Suas atividades têm como objetivo principal de apoiar a implementação do Programa de Saúde da Família no Estado de Minas Gerais, atuando na formação de recursos humanos e no desenvolvimento de novas tecnologias na assistência, no ensino e na educação permanente dos profissionais das equipes de saúde da família (UNI-

No que concerne À formação e capacitação de pessoal, é necessário que as ações ocorram na direção de se construir novas formas de se lidar com o conhecimento, o que inclui, de modo marcante, o espaço transdisciplinar e não tradicional para a produção e incorporação do saber. VERSIDADE FEDERAL DE MINAS GERAIS, 1997). O trabalho realizado pelo Pólo é implementado através de cinco (5) Sub-Projetos, articulados entre si e coordenados por docentes da Escola de Enfermagem e Faculdade de Medicina da UFMG. Entre eles, encontra-se o Subprojeto "Produção e Incorporação de Tecnologias Apropriadas", cujas experiências estão relatadas neste artigo. Este Sub-Projeto tem como objetivos desenvolver, incorporar e disseminar tecnologias, metodologias de trabalho e conhecimentos relacionados à estratégia de saúde da família; estabelecer pontes com os demais Sub-Projetos do Pólo, atendendo suas demandas específicas, além de congregar as Unidades Acadêmicas da UFMG, e seus órgãos complementares. Suas atividades não têm um fim nelas mesmas; por sua natureza, elas são meio que viabiliza a consecução de objetivos dos demais Sub-Projetos do Pólo. Uma de suas principais pontas de lança é a criação de "infovias" para possibilitar o acesso à informação e a construção coletiva do saber (UNIVERSIDADE FEDERAL DE MINAS GERAIS, 1998).

${ }^{1}$ Enfermeira, Professora Adjunto I do Departamento de Enfermagem Materno-Infantil e Saúde Pública da Escola de Enfermagem da Universidade Federal de Minas Gerais/UFMG. Coordenadora do Subprojeto Produção e Incorporação de Tecnologias Apropriadas do Pólo de Capacitação, Formação e Educação Permanente de Pessoal para Saúde da Família da UFMG. Doutora em Enfermagem.

${ }^{2}$ Enfermeira, Professora Assistente III do Departamento de Enfermagem Aplicada da Escola de Enfermagem da Universidade Federal de Minas Gerais/UFMG. Coordenadora do Centro de Tecnologia Educacional da EEUFMG. Integrante do Sub-Projeto Produção e Incorporação de Tecnologias Apropriadas do Pólo de Capacitação, Formação e Educação Permanente de Pessoal para Saúde da Família da UFMG. Doutoranda pela EEUSP/Ribeirão Prêto-SP

${ }^{3}$ Enfermeira, Professora Auxiliar II do Departamento de Enfermagem Básica da Escola de Enfermagem da Universidade Federal de Minas Gerais/UFMG. Sub-Coordenadora do Centro de Tecnologia Educacional da EEUFMG. Integrante do Sub-Projeto Produção e Incorporação de Tecnologias Apropriadas do Pólo de Capacitação, Formação e Educação Permanente de Pessoal para Saúde da Família da UFMG. Mestranda pela EEUFMG

${ }^{4}$ Acadêmica de Enfermagem do VI Período do Curso Graduação da EEUFMG. Bolsista de Extensão do Pólo de Capacitação, Formação e Educação Permanente de Pessoal para Saúde da Família da UFMG. 


\section{PRODUÇÃO E INCORPORAÇÃO DE TECNOLOGIAS: UM DESAFIO NA EDUCAÇÃO PERMANENTE EMSAÚDE}

A organização da sociedade tem se dado por transformações significativas evidenciadas nas mudanças dos processos de trabalho e nos modos de relacionamento dos homens entre si e com o ambiente em que vivem. Estas transformações advêm, entre outras causas, da produção e incorporação de tecnologias nos vários campos da ciência, não só no que se refere ao seu resultado, como nas formas de produzi-lo, ganhando expressiva modificação, em especial, na automação dos processos e na homogeneização do produto. A despeito das transformações decorrentes das mudanças tecnológicas, há que se considerar os aspectos culturais arraigados no cotidiano das pessoas, que se mostram sob a forma de resistência às inovações. Este comportamento limita a possibilidade de ampliação das formas de produção e incorporação de saberes. Limitação que transita também pela dificuldade do trabalho interdisciplinar, visto que o mesmo exige uma "des"construção de práticas e de saberes, visando sua construção coletiva.

$\mathrm{Na}$ área da saúde, a produção do saber tem ocorrido de forma fragmentada, levando em conta as características de complementaridade intrínsecas do ato de cuidar e os diversos profissionais nele envolvidos. No tocante à atenção básica de saúde, a preocupação com a incorporação tecnológica tem raízes históricas, onde o fator tecnologia é relevante, "uma vez que responde a questões de 'como, para que, para quem, por quanto, por quem' serão executadas as ações de saúde" (Paim, 1981 , p. 80). Especificamente no âmbito da enfermagem brasileira, as preocupações com a adequação da tecnologia à realidade brasileira remontam de 1981, quando um dos temas centrais do $33^{\circ}$ Congresso Brasileiro de Enfermagem discutiu a tecnologia apropriada no âmbito da atenção básica de saúde, sua importância, dinamicidade e determinações sociais, políticas, econômicas e culturais. Empregála como instrumento de educação permanente em saúde tem sido vivenciado, por nós, como um processo desafiante. Segundo Davini \& Roschke, (1994) educação permanente em saúde "supõe mudança radical nas práticas de pensar, projetar e realizar a educação. Mais ainda, supõe assumir solidariamente com as instituições de saúde, as múltiplas dimensões de seu processo de transformação" (p.141). Tudo o que até agora foi feito e projetado nas atividades do Sub-Projeto, vem permeado pela constante indagação: como adequar tecnologias num processo que exige mudanças nas formas de pensar e fazer, no contexto de uma estratégia como a de saúde da família, que exige rupturas e construção de novos paradigmas em saúde e educação?

\section{RESULTADOS}

Após a constituição do grupo de trabalho, as atividades do Sub-Projeto foram projetadas considerando os dados obtidos através de levantamento de recursos institucionais-potencial humano e tecnológico da Escola de Enfermagem , da Faculdade de Medicina e de toda a UFMG para serem "polarizados" nas atividades do Pólo e de recursos comunitários, onde as equipes de saúde da família haviam sido implantadas Também foram levantadas as demandas dos demais Sub-Projetos em relação à incorporação e/ou produção de tecnologias. Concomitante a estas atividades, foi criado um banco de dados de pessoas, instituições, demais Pólos e projetos para estabelecimento de contatos e parcerias. As demais atividades foram:

- a criação da logomarca, do folder e do endereço eletrônico do Pólo: secretaria @ polopsf.ufmg.br . Para viabilizar esta atividade, foi adquirido um servidor próprio para o Pólo;

- criação da home-page do Pólo (http//www.polopsf.ufmg.br), como espaço para divulgação de todos os eventos e cursos oferecidos pelo Pólo, dando acesso aos links de instituições parceiras. Sua principal finalidade entretanto, é ser o espaço para a realização da consultoria a distância, mencionada no próximo ítem;

- iniciada em outubro de 1999, a consultoria a distância já está disponível e amplamente divulgada. As consultas formuladas são enviadas para o e-mail eadcons @ polopsf.ufmg.br e direcionadas para os consultores docentes da Escola de Enfermagem, Faculdade de Medicina, Hospital das Clínicas, bem como das demais Unidades Acadêmicas da UFMG, com o intuito de formar e consolidar o grupo 
de editores e consultores do Pólo. A incorporação desta nova forma de construir e trocar conhecimentos e saberes, tem sido um dos maiores desafios deste Sub-Projeto. Apesar de todos os esforços, sua incorporação tem sido mais lenta do que a esperada. Para sistematizar o acesso à consultoria, sete (7) áreas temáticas principais foram criadas: 1) Saúde da Criança e do Adolescente, 2) Saúde do Adulto e do Idoso, 3) Saúde da Mulher, 4) Saúde Mental, 5) Clínica Cirúrgica, 6) Saúde Coletiva/ Gerenciamento de Serviços de Saúde e 7) Atenção às Doenças Transmissíveis/DST.

\section{PERSPECTIVAS DE NOVAS ATIVIDADES}

Em integração com os Sub-Projetos "Capacitação de Profissionais de Nível Universitário" e "Capacitação de Pessoal de Nível Médio", após levantamento das demandas educacionais dos àlunos egressos dos Cursos Introdutórios e de Especialização em Saúde da Família já ministrados pelo Pólo, o Sub-Projeto vai implementar um Programa de Educação Permanente.

Pretende-se incluir na home-page um texto informativo mensal - Tema em Debate, para discussão. O mesmo será elaborado a partir das demandas dos usuários, de acordo com as questões abordadas com maior freqüência pelos mesmos nas consultorias. Este texto será elaborado por docentes e/ou acadêmicos da Universidade. O tema mais discutido, a cada mês, dará origem a mais um recurso na home-page : o FAQ - Frequently Asked Questions.

Outras perspectivas de atuação do Sub-Projeto são:

- contactar periódicos da área de saúde visando a publicação de encartes ou edições especiais para divulgar a produção científica do Pólo;

- contactar os órgãos de pós-graduação das Unidades Acadêmicas da UFMG, visando a criação de núcleos e linhas de pesquisa na área de saúde da família.

\section{CONCLUSÃO}

Na sua concepção essencial, o Pólo de Capacitação, Formação e Educação Permanente de Pessoal para Saúde da Família da UFMG está voltado para fazer acontecer mudanças no modelo da atenção a saúde, capazes de impactar a implantação do Sistema Único de Saúde- SUS. No que concerne à formação e capacitação de pessoal, é necessário que as ações ocorram na direção de se construir novas formas de se lidar com o conhecimento, o que inclui, de modo marcante, o espaço transdisciplinar e não tradicional para a produção e incorporação do saber. A denominação "Construindo Caminhos para a Troca de Saberes"traz a conotação de que o conhecimento não pressupõe o ensino livresco, deslocado da realidade do educando, nem o coloca na condição passiva de receptor de informações. Ele, a clientela que atende, as suas vivências dentro e fora da Universidade, são produtoras do conhecimento que deve ser compartilhado e refletido. É com esta filosofia que o Sub-Projeto "Produção e Incorporação de Tecnologias Apropriadas" tem procurado pautar suas atividades.

\section{REFERÊNCIAS BIBLIOGRÁFICAS}

DAVINI, M.C.; ROSCHKE, M.A.C. Conocimiento significativo: el diseño de un proyecto de educación permanente en salud. In: HADDAD, J.; ROSCHKE, M.A.C.; DAVINI, M.C. Educación permanente de personal de salud. Série Desarrollo de Recursos Humanos n 100, Washington: OMS/OPS, 1994.

PAIM, E. R. A Enfermagem e a Tecnologia Apropriada; Adequação da Prática à Realidade Brasileira. In: CONGRESSO BRASILEIRO DE ENFERMAGEM, 33., Manaus, 1981. Tema III. Anais...ABEn: Manaus, 1981.

UNIVERSIDADE FEDERAL DE MINAS GERAIS. Pólo de Capacitação, Formação e Educação Permanente de Pessoal para Saúde da Família. Proposta de Implantação. Belo Horizonte-MG, 1997.

UNIVERSIDADE FEDERAL DE MINAS GERAIS. Pólo de Capacitação, Formação e Educação Permanente de Pessoal para Saúde da Família. Sub-Projeto Produção e Incorporação de Tecnologias Apropriadas. Belo Horizonte-MG, 1998. 